\title{
A comparison among different way to perform the lock-in multi-frequency test in a CFRP composite sample
}

\author{
by E.D’Accardi*, D.Palumbo* and U.Galietti*
}

\begin{abstract}
* Politecnico di Bari, Department of Mechanics, Mathematics \& Management, Via Orabona 4, 70125 Bari, Italy, ester.daccardi@poliba.it, davide.palumbo@poliba.it,umberto.galietti@poliba.it
\end{abstract}

\begin{abstract}
Active thermography for non-destructive testing enables a contactless, fast, remote and not expensive control of materials and structures. Different works have confirmed the potentials of lock-in thermography as a flexible technique for its peculiarity to be performed by means of a low-cost set-up. In this work, a thermographic basic equipment with halogen lamps and a microbolometer IR camera was used for evaluating the effect different excitation modes. A CFRP sample with imposed defects has been used with the aim to give some quantitative indications about defects detection. In this regard, the capability of the technique was evaluated by adopting different heating configurations and modulated frequencies.
\end{abstract}

\section{Introduction}

Composite materials are used in many fields and engineering applications thanks to the possibility they offer to design lightweight structures with high mechanical properties. The mechanical behaviour of composite structures can be affected by the presence of defects that can occur during the manufacturing process or in-service conditions. In this regard, non-destructive tests, such as thermography [1,12], can be necessary to detect and characterized defects.

Lock-in thermography (LT) $[3,12]$ is among the most used active thermography techniques. It makes use of a modulated optical stimulation to heat the sample by means of a thermal wave (typically sinusoidal or square) which propagates into the material. Amplitude and phase data represent the results to a periodic excitation of the specimen surface at a fixed modulated frequency. The capability of LT thermography to detect defects in Carbon Fiber Reinforced Plastics (CFRP) and in Glass Fiber Reinforced Polymers (GFRP) composite materials has been demonstrated in different works $[1,6]$. Generally, the LT technique is performed by using a sinusoidal thermal wave with a heating source that stimulates the material at a fixed frequency value $[3,6]$. This frequency allows for investigating only a limited depths range. It follows that many tests are necessary to explore thick structures. To reduce the testing time, Palumbo et al. [4], proposed the use of a modulated square wave as a heat source in order to obtain from one test some information about high-order frequencies proportional to the principal one. As it was demonstrated from other works [4, 5], the square wave excitation allows for obtaining significant phase data, in terms of signal to noise ratio, up to the $5^{\text {th }}$ harmonic of the principal one. Furthermore, very few works in the literature give some indications about the influence of process parameters such as the number of cycles and the number of frames for cycles, on the quality of results in terms of capability in defect detection and characterization [4].

In this work, lock-in tests have been performed on a CFRP sample with imposed defects using different excitation modes. In particular, three different excitation waveforms were used, sinusoidal, square and the superimposition of two square wave (named multifrequency approach). This latter approach has been performed in two ways: via hardware (controlling independently halogen lamps) and via software (composing the resulting signal). Moreover, the effect of processing parameters such as the number of cycles, the frame rate and the polynomial model used for describing the mean temperature, has been investigated in terms of phase contrast and phase data noise.

\section{Theory}

Generally, the LT technique is carried out by stimulating the material with a modulated sinusoidal heat source at a fixed frequency. This frequency allows to investigate the material to a given depth as reported in Eq. (1).

$$
\varphi(z)=\frac{2 \pi z}{\lambda}=\frac{z}{\mu} \quad \text { with } \mu=\sqrt{\frac{2 k}{\varpi \rho c_{p}}}=\sqrt{\frac{2 \alpha}{\varpi}}
$$

with $\lambda$ is the thermal wavelength and $\mu$ the thermal diffusion length, $k$ is the thermal conductivity, $\rho$ is the density, $\mathrm{c}_{p}$ is the specific heat at constant pressure, $\omega$ is the modulation frequency and $\alpha$ is the thermal diffusivity.

This equation indicates that higher modulation frequencies restrict the analysis in a near-surface region, while low-frequency thermal waves propagate deeper but very slowly [3, 7].

In the case of a square wave excitation, the thermal response as can be seen as the sum of a singular sinusoidal waves; by considering the main harmonics up to 5 , the Eq. (2) allows to obtain information about amplitude and phase signal of high-order excitation frequencies $[4,5]$ : 


$$
T_{m}(t)=a+b t+\Delta T_{1} \sin \left(w t+\varphi_{1}\right)+\Delta T_{3} \sin \left(3 w t+\varphi_{3}\right)+\cdots+\Delta T_{n} \sin \left(n w t+\varphi_{n}\right)
$$

where $T_{m}$ is the mean temperature of each pixel, $\Delta T_{n}$ and $\varphi_{n}$ with $\mathrm{n}=1,3,5, . . \mathrm{n}$ are the amplitude and phase of a Fourier decomposition, and $a$ and $b$ are the constants used to model the average temperature growth of the material.

In this work, all the constants were obtained through a least-square fit method by imposing the model of Eq. (2) to the thermal signal of each pixel and by considering the terms up to $n=5$ [4] and the average temperature growth of the material will be investigated by changing the order of the polynomial degree, as will be explained in detail in the next paragraphs.

\section{Materials and experimental set-up}

The sample considered for the following investigations is made of CFRP composite material and it has been laminated with the use of fabric pre-peg with fibre T300 (Figure 1). All plies (n. 25) are oriented at $0 \% 90^{\circ}$ for a total thickness of $5 \mathrm{~mm}$. The geometry of the defects is circular. The defects are produced with 2 layers of release film MR-1 RED and 2 layers of flash breaker. Different depths in terms of interested plies and different diameters were considered for simulating defects. Different materials, with also different thermophysical properties have used to produce defects (Table 1).

The thermographic set-up is shown in Figure 2. Six halogen lamps with a total power of 4000W were controlled by the MultiDES system (DES S.r.I.) to stimulate the specimen. The IR camera A655sc (FLIR System) based on a microbolometer detector was used to perform the thermographic tests. The final geometric resolution is $0.68 \mathrm{~mm} /$ pixel. The specimen was set as a cantilever beam configuration in order to avoid possible heat conduction effects due to supports in direct contact with its opposite side.
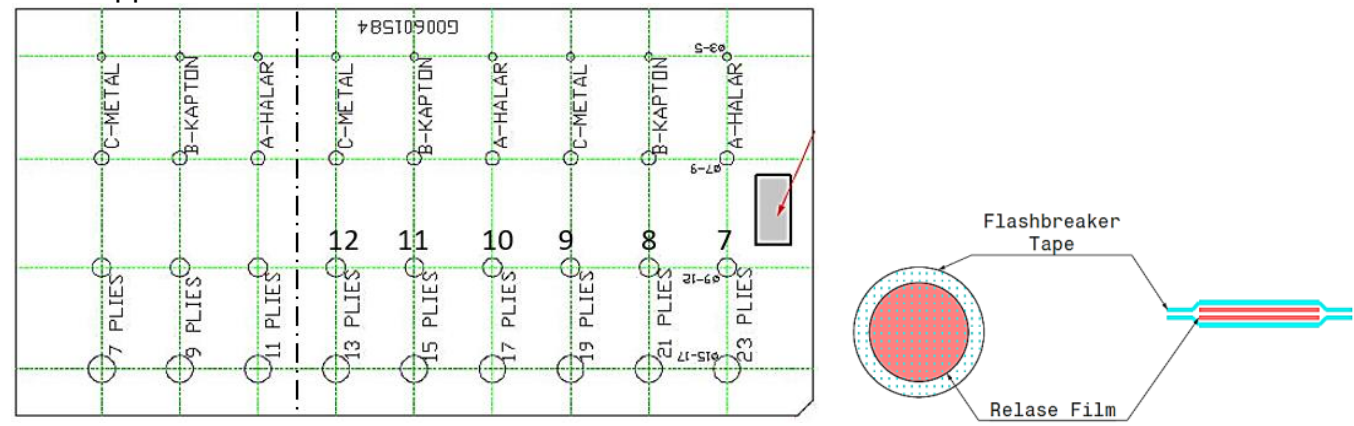

Fig. 1. CFRP composite sample and imposed defects (the part inspected is indicated by the dotted line).

Table 1. Material, defect depths and diameters.

\begin{tabular}{|c|c|c|c|}
\hline \multirow{2}{*}{ Material } & \multicolumn{3}{|c|}{ Defect depth (starting from the inspected side) } \\
\hline A-HALAR & $0.4 \mathrm{~mm} \mathrm{23} \mathrm{Pl.}$ & $1.6 \mathrm{~mm} \mathrm{17} \mathrm{PI}$ & $2.8 \mathrm{~mm} \mathrm{11} \mathrm{Pl}$. \\
\hline B-KAPTON & $0.8 \mathrm{~mm} \mathrm{21} \mathrm{Pl.}$ & $2 \mathrm{~mm} 15 \mathrm{Pl}$ & $3.2 \mathrm{~mm} \mathrm{9} \mathrm{Pl}$. \\
\hline C-METAL & $1.2 \mathrm{~mm} \mathrm{19} \mathrm{Pl.}$ & $2.4 \mathrm{~mm} 13 \mathrm{PI}$ & $3.6 \mathrm{~mm} \mathrm{7} \mathrm{Pl}$. \\
\hline
\end{tabular}

\begin{tabular}{|c|c|}
\hline \multicolumn{2}{|c|}{ Defect diameter (starting from the first row in Fig. 1 ) } \\
\hline Release film (mm) & Flashbreaker tape (mm) \\
\hline 3 & 5 \\
\hline 7 & 9 \\
\hline 9 & 12 \\
\hline 15 & 17 \\
\hline
\end{tabular}
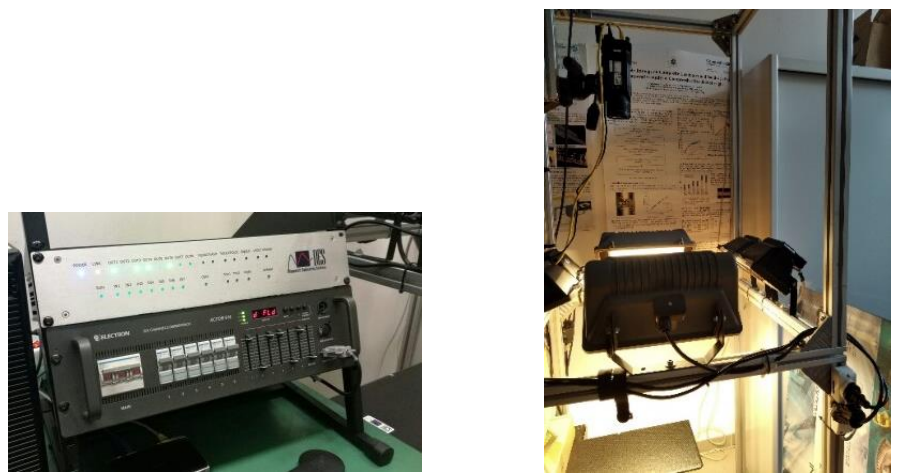

Fig. 2. Lock-in thermography set-up.

\section{Experimental campaign and method of analysis}

An extensive experimental campaign has been carried out for investigating different excitation modes, test and process parameters. In Table 2 are reported all the test parameters used for each test. In particular, a frame rate of $5 \mathrm{~Hz}$ 
has been used for all the tests and excitation periods ranging from $4.5 \mathrm{~s}$ to $90 \mathrm{~s}$. These periods allowed for identifying defect depths up to $2.4 \mathrm{~mm}$ (corresponding to the left part of the specimen in Figure 1). Three repetitions for each test were carried out. In red were reported the tests used in this work.

Different modes of excitation were used for the tests, corresponding to sinusoidal wave, square wave, and multifrequency waves. The multifrequency approach has been performed in two ways: controlling independently the halogen lamps with two square waves at different periods (via hardware, MFH) and superimposing via software two square waves signals at different periods (MFS). The graphical and schematic explanations of a multifrequency experiment both software and hardware are explained in Figure. 3, for a period of 45-90 seconds. In particular, it is reported the temperature signal obtained by analysing a $3^{\star} 3$ matrix in a sound area of the sample. It is important to notice that in MFS approach the power of all the lamps follows the signal obtained superimposing the two square waves (Figure 3a) while, for the MFH approach, the lamps on the opposite side (two lamps for side) follow the two different periods, independently (Figure $3 b$ ). The temperatures reached in both approaches are comparable. As already said, similar tests for comparison were carried out by exciting the specimen with sine waves and square waves, with $50 \%$ of the power, in order to compare the tests to the single period. However, it seems clear that using two different periods of excitation during the same test leads to reach higher temperatures than the single period (Figure 3c).

Other test and process parameters were investigated such as:

- the number of excitation cycles and their relative position within the acquired sequence (Figure 4c, Table 3)

- the polynomial degree approximation of the mean temperature (Figure 4a, Table 3),

$T_{m}(t)=a+b t+\Delta T_{1} \sin \left(w t+\varphi_{1}\right)+\Delta T_{3} \sin \left(3 w t+\varphi_{3}\right)+\Delta T_{n} \sin \left(5 w t+\varphi_{5}\right)$

$T_{m}(t)=a+b t+c t^{2}+\Delta T_{1} \sin \left(w t+\varphi_{1}\right)+\Delta T_{3} \sin \left(3 w t+\varphi_{3}\right)+\Delta T_{5} \sin \left(5 w t+\varphi_{5}\right)$

$T_{m}(t)=a+b t+c t^{2}+d t^{3}+\Delta T_{1} \sin \left(w t+\varphi_{1}\right)+\Delta T_{3} \sin \left(3 w t+\varphi_{3}\right)+\Delta T_{5} \sin \left(5 w t+\varphi_{5}\right)$

- the number of frames per cycle, sub-sampling the original sequence and obtaining 3 frame rate levels that correspond to 3 different numbers of frames per cycle (Table 3);

In Table 3 are summarised the analysis carried out for each parameter. For the analyses, the IRTA 2 [13] software and the MATLAB software, academic version, were used. The comparisons will be carried out subtracting the obtained maps and reporting for each map some significant values, such as the mean and the standard deviation of the phase. The phase contrast maps were obtained subtracting the average of the sound area, calculated as the sum of all the areas surrounding every single defect-i.e. figure 5 (for a total of about 20000 pixels). In this way, a comparison on the same scale is obtained. A final comparison defect by defect (matrix $3^{*} 3$ as mean value for each defect) will then be shown in detail in section 6 (numbering of the considered defects in Figure 1) considering for each individual defect only its sound area (about 1000 pixels around the considered defect).

Table 2. Experimental campaign.

\begin{tabular}{|c|c|c|c|c|c|c|}
\hline Waveforms & $\begin{array}{l}\text { Excitation } \\
\text { Periods (s) }\end{array}$ & $\begin{array}{l}\text { Acquisition } \\
\text { duration (s) }\end{array}$ & $\begin{array}{c}\text { Frame rate } \\
(\mathrm{Hz})\end{array}$ & $\begin{array}{l}\text { Number } \\
\text { of cycles }\end{array}$ & $\begin{array}{c}\% \\
\text { Energy }\end{array}$ & $\begin{array}{l}\text { Excitation periods (s- after the } \\
\text { test, available for the analysis) }\end{array}$ \\
\hline \multirow{2}{*}{$\begin{array}{l}\text { Multifrequency } \\
\text { software (MFS) }\end{array}$} & $22.5-45$ & 135 & \multirow{2}{*}{$5 \mathrm{~Hz}$} & \multirow{2}{*}{$6-3$} & \multirow{2}{*}{ Fig.3 a } & $4.5,7.5,9,15,22.5,45$ \\
\hline & $45-90$ & 270 & & & & $9,15,18,30,45,90$ \\
\hline \multirow{2}{*}{$\begin{array}{c}\text { Multifrequency } \\
\text { hardware (MFH) }\end{array}$} & $22.5-45$ & 135 & \multirow{2}{*}{$5 \mathrm{~Hz}$} & \multirow{2}{*}{$6-3$} & \multirow{2}{*}{ Fig.3 b } & $4.5,7.5,9,15,22.5,45$ \\
\hline & $45-90$ & 270 & & & & $9,15,18,30,45,90$ \\
\hline \multirow{9}{*}{ Sine } & 4.5 & 135 & \multirow{9}{*}{$5 \mathrm{~Hz}$} & 30 & \multirow{9}{*}{50} & 4.5 \\
\hline & 7.5 & 135 & & 18 & & 7.5 \\
\hline & 9 & 270 & & 30 & & 9 \\
\hline & 15 & 270 & & 18 & & 15 \\
\hline & 18 & 270 & & 15 & & 18 \\
\hline & 22.5 & 135 & & 6 & & 22.5 \\
\hline & 30 & 270 & & 9 & & 30 \\
\hline & 45 & 270 & & 6 & & 45 \\
\hline & 90 & 270 & & 3 & & 90 \\
\hline \multirow{3}{*}{ Square } & 22.5 & 135 & \multirow{3}{*}{$5 \mathrm{~Hz}$} & 6 & \multirow{3}{*}{50} & $4.5,7.5,22.5$ \\
\hline & 45 & 270 & & 6 & & $9,15,45$ \\
\hline & 90 & 270 & & 3 & & $18,30,90$ \\
\hline
\end{tabular}

Table 3. Excitation period for the different defect depths (Eq.1).

\begin{tabular}{|c|c|c|c|c|c|c|c|c|c|}
\hline thermal diffusivity CFRP $\alpha\left(\mathrm{mm}^{2} / \mathrm{s}\right)$ & 0,42 & & & \\
\hline depth $(\mathrm{mm})$ & 3,6 & 3,2 & 2,8 & 2,4 & 2,0 & 1,6 & 1,2 & 0,8 & 0,4 \\
\hline period (s) & 96,9 & 76,6 & 58,6 & 43,1 & 29,9 & 19,1 & 10,8 & 4,8 & 1,2 \\
\hline
\end{tabular}




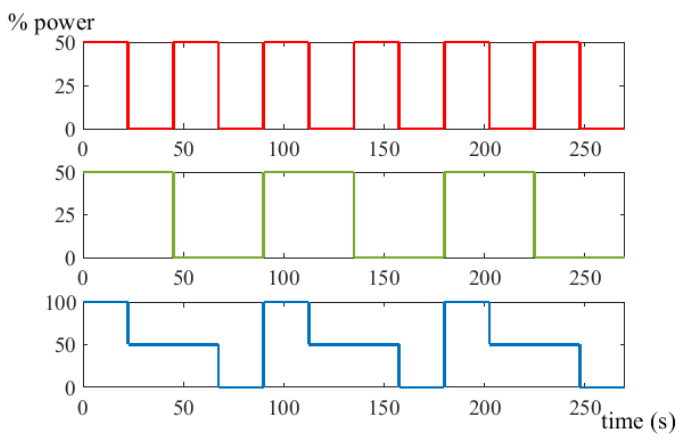

(a)

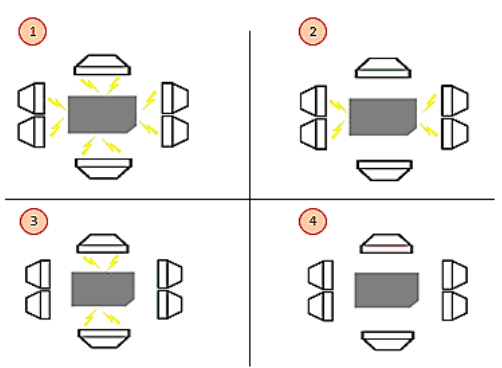

(b)

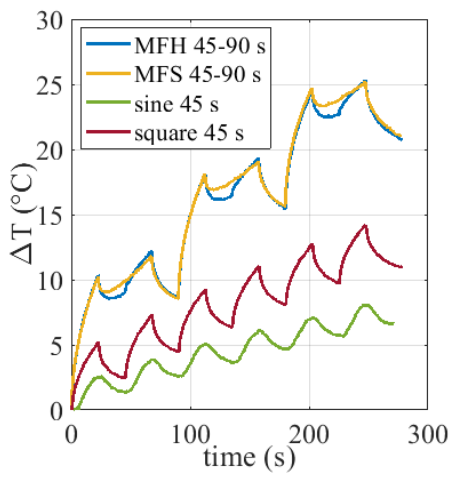

(c)

Fig. 3. Multifrequency software (a), multifrequency hardware (b), obtained and analysed waveforms (c).

Table 3. Analyses chosen by varying the different testing and analysis parameters.

\begin{tabular}{|c|c|c|c|c|}
\hline Waveforms & $\begin{array}{l}\text { Excitation } \\
\text { Periods (s) }\end{array}$ & $\begin{array}{c}\text { Polynomial } \\
\text { degree }\end{array}$ & $\begin{array}{c}\text { Analysis } \\
\text { cycles }\end{array}$ & $\begin{array}{l}\text { Analysis frame } \\
\text { rate }(\mathrm{Hz})\end{array}$ \\
\hline \multirow{2}{*}{$\begin{array}{l}\text { Multifrequency } \\
\text { software (MFS) }\end{array}$} & 4.5 & 1 & 2 & 1.67-75 frame \\
\hline & 7.5 & 2 & 3 & 2.5-112 frame \\
\hline \multirow{2}{*}{$\begin{array}{c}\text { Multifrequency } \\
\text { hardware (MFH) }\end{array}$} & 9 & 3 & 4 & $5-225$ frame \\
\hline & 15 & & 6 & \\
\hline Sine & 18 & & $1-3$ & \\
\hline \multirow[t]{4}{*}{ Square } & 22.5 & & $2-5$ & \\
\hline & 30 & & $3-6$ & \\
\hline & 45 & & & \\
\hline & 90 & & & \\
\hline
\end{tabular}

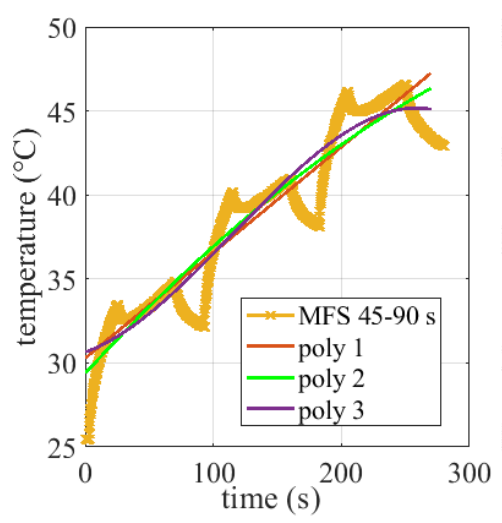

(a)

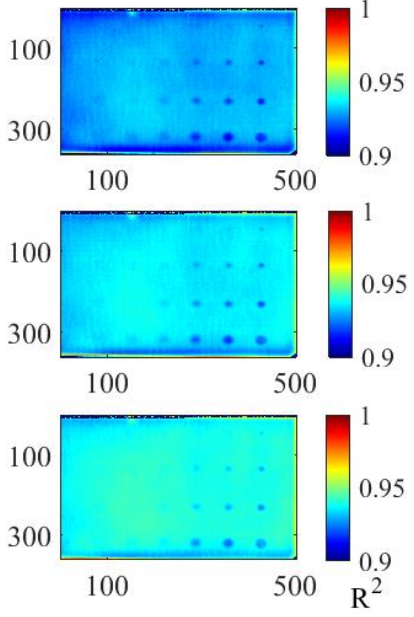

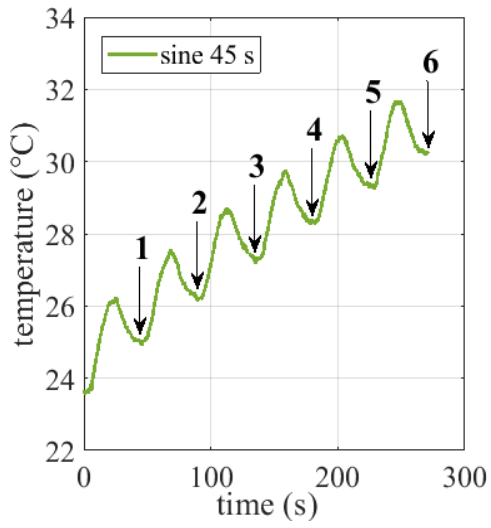

(b)

Fig. 4. The order of the polynomial degree to model the average temperature growth of the material and how the coefficient of determination changes (a); scheme representing the number of cycles analysed and their position.

\section{Results}

Figure 5 shows an example of results obtained by analysing the MFS 45-90 seconds test applying the algorithm described in theory, for the period of $45 \mathrm{~s}$. The first harmonic obtained as a phase map and the relative phase contrast maps are shown as an example when the mean value of the sound area is subtracted pixel by pixel. Figure 6, on the other hand, shows all the results obtained in terms of phase contrast maps from the same MFS test $45-90 \mathrm{~s}$. Two main harmonics are obtained, $45 \mathrm{~s}, 6$ cycles, 1350 frames, $90 \mathrm{~s}, 3$ cycles, 750 frames and the related subsequent harmonics $15 \mathrm{~s}$ (45 s), 6 cycles, 1350 frames $\left(3^{\text {rd }}\right), 9 \mathrm{~s}(45 \mathrm{~s}), 6$ cycles, 1350 frames $\left(5^{\text {th }}\right), 30 \mathrm{~s}(90 \mathrm{~s}), 3$ cycles, 1350 frames $\left(3^{\text {rd }}\right), 18 \mathrm{~s}(90 \mathrm{~s}), 3$ cycles, 1350 frames $\left(5^{\text {th }}\right)$. The mean and standard deviation values have also been calculated for the sound area and shown in Table 4. The higher harmonics are very noisy than the main ones but, show an indication of the results that can be obtained at lower periods. The excitation period of $45 \mathrm{~s}$ is the one that returns the largest number of indications; instead, 
the main period of 90 seconds appears to be too long for the depths investigated, but in a multifrequency test (hardware or software) it leads to an increase in terms of average temperature level and therefore in the signal to noise ratio (Figure 4b. and comparisons below in subsection 5.14).
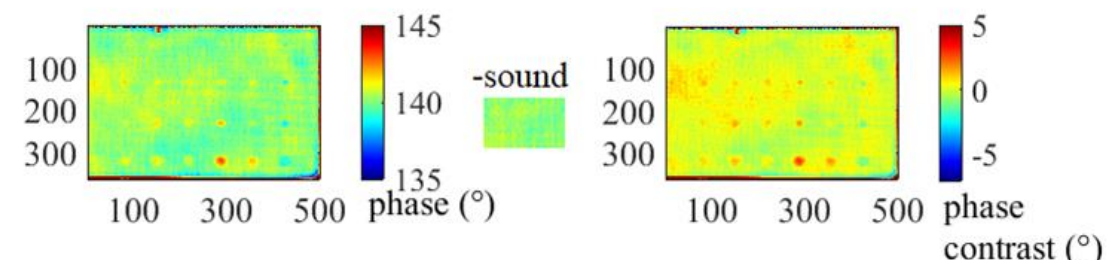

Fig. 5. MFS 45-90 seconds, phase map and related phase contrast map 45 seconds $1^{\text {st }}$ harmonic, 6 cycles, 270 $s$, approximation polynomial degree 1. Phase map and phase contrast map obtained by subtracting the phase mean value in the sound area.
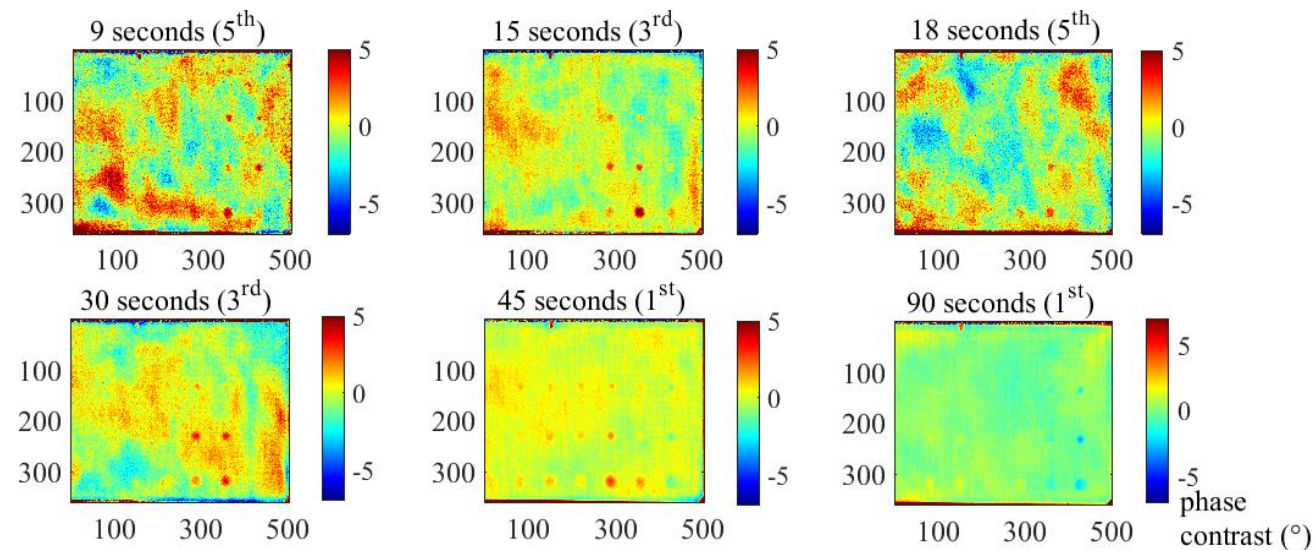

Fig. 6. Contrast phase maps corresponding to 6 different periods and 3 different harmonics (MFS $45-90 \mathrm{~s}, 5 \mathrm{~Hz}$, 1350 frames, approximation polynomial degree 1).

Table 4. Mean and standard deviation values of the sound area (phase maps in Figure 6).

\begin{tabular}{|c|c|c|c|c|c|c|}
\hline $\begin{array}{c}\text { Period of excitation }(\mathrm{s}) \text { and } \\
\text { corresponding harmonics }\end{array}$ & $9 \mathrm{~s}\left(5^{\text {th }}\right)$ & $15 \mathrm{~s}\left(3^{\text {rd }}\right)$ & $18 \mathrm{~s}\left(5^{\text {th }}\right)$ & $30 \mathrm{~s}\left(3^{\text {rd }}\right)$ & $45 \mathrm{~s}\left(1^{\text {st }}\right)$ & $90 \mathrm{~s}\left(1^{\text {st }}\right)$ \\
\hline Sound mean value $\left(^{\circ}\right)$ & -26.11 & 146.90 & -34.76 & 141.63 & 140.22 & 139.47 \\
\hline Sound std value $\left(^{\circ}\right)$ & 1.92 & 1.05 & 2.42 & 1.22 & 0.96 & 1.21 \\
\hline
\end{tabular}

\subsection{Influence of the polynomial degree approximation of the mean temperature}

The results obtained from the analysis MFS are shown (MFS 22.5-45 $\mathrm{s}$ and 45-90 s) in Figures 7-9, in which are reported the main harmonics for a low $22.5 \mathrm{~s}$ (Figure 7), medium (Figure 8) and high (Figure 9) period, changing the degree of approximation from 1 to 3 . In the case of shorter and longer periods, only the "difference maps" are reported, obtained for subtraction with the phase map corresponding to the degree 1 pixel by pixel. In Table 5 are reported mean and standard deviation values of phase contrast maps (sound area) and "difference images". Standard deviation values evaluated in the sound areas show lower values in correspondence of the polynomial degree 3 . However, significant differences were observed only for the higher period (90 s). It is important to underline that the time taken to process lock-in data increases as the polynomial degree increases. In this context it should also be stressed that, in the case of analyses with longer excitation periods i.e. 90 seconds, there is an increase in terms of standard deviation values (Table 5). The standard deviation increasing could be due to the edge effects (Figure 9) that become more significant for higher periods. Table 5 shows also the standard deviation values of the phase contrast map at 45 seconds both for the test MFS 22.5-45 s and the test MFS $45-90 \mathrm{~s}$. It seems that the level of noise is better in the case of 22.5-45 s, so when a lower period is used together with the period of 45 seconds. This interesting point will be investigated better in future works.
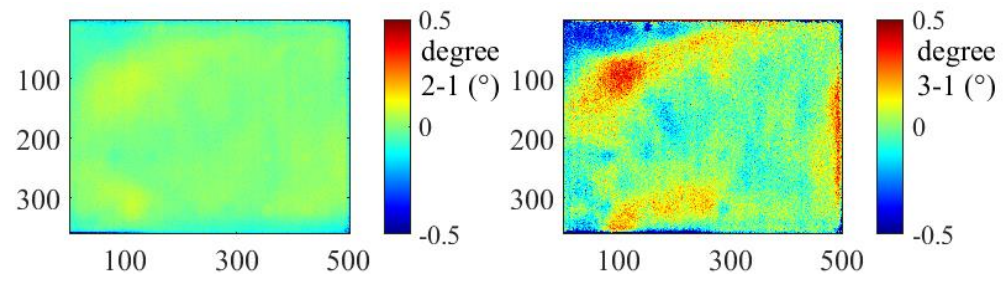

Fig. 7. MFS 22.5-45 s, "difference maps" related to the excitation period of 22.5 seconds (6 cycles, $5 \mathrm{~Hz}, 675 \mathrm{frames}$ ). 

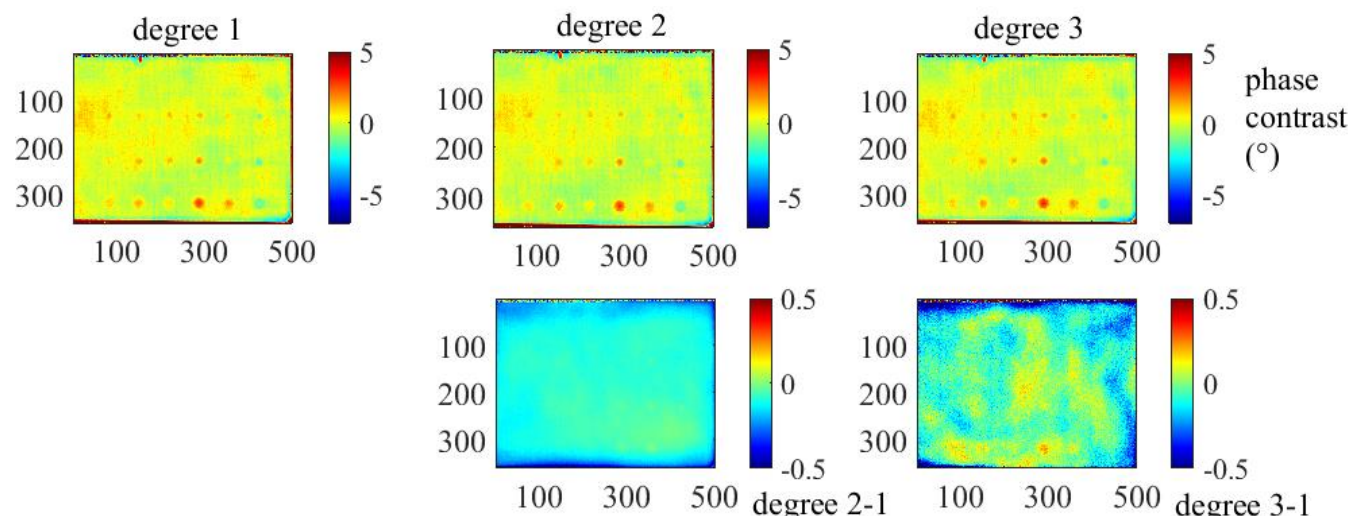

Fig. 8. MFS $45-90 \mathrm{~s}$, phase contrast maps excitation period 45 seconds (6 cycles, $5 \mathrm{~Hz}, 1350$ frames) for 3 different polynomial degree $\left(1^{\text {st }}, 3^{\text {rd }}\right.$ and $5^{\text {th }}$ as indicated) and related "difference maps".

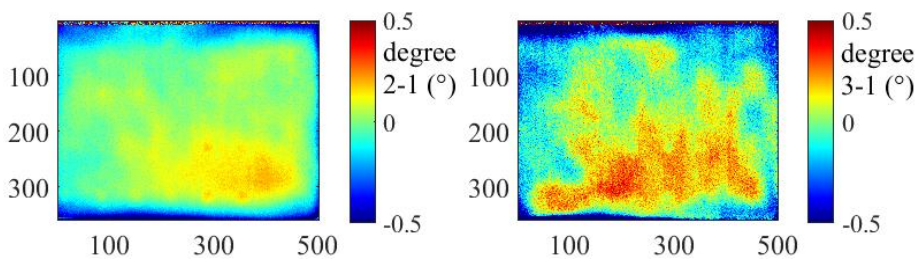

Fig. 9. MFS 45-90 s, "difference maps" related to the excitation period of 90 seconds (3 cycles, $5 \mathrm{~Hz}, 1350$ frames).

Table 5. Mean and standard deviation values in the sound area of the investigated phase maps, MFS 22.5-45 and $45-90 \mathrm{~s}$

\begin{tabular}{|c|c|c|c|c|c|c|c|}
\hline Period (s- MFS) & Polynomial degree & 1 & 2 & 3 & Differences maps & Degree 2-1 & Degree 3-1 \\
\hline \multirow{2}{*}{22.5} & Sound mean value $\left(^{\circ}\right)$ & 142.01 & 141.58 & 144.51 & Mean value $\left(^{\circ}\right)$ & 0.00 & -0.01 \\
\hline & Sound std value $\left(^{\circ}\right)$ & 0.72 & 0.71 & 0.70 & Std value $\left(^{\circ}\right)$ & 0.04 & 0.17 \\
\hline \multirow{2}{*}{$45(22.5-45 \mathrm{~s})$} & Sound mean value $\left({ }^{\circ}\right)$ & 145.39 & 139.88 & 141.40 & Mean value $\left({ }^{\circ}\right)$ & 0.00 & -0.02 \\
\hline & Sound std value $\left(^{\circ}\right)$ & 0.87 & 0.86 & 0.83 & Std value $\left(^{\circ}\right)$ & 0.08 & 0.23 \\
\hline \multirow{2}{*}{45 (45-90 s) } & Sound mean value $\left({ }^{\circ}\right)$ & 140.22 & 139.72 & 143.00 & Mean value $\left({ }^{\circ}\right)$ & 0.03 & 0.04 \\
\hline & Sound std value $\left(^{\circ}\right)$ & 0.96 & 0.94 & 0.92 & Std value $\left(^{\circ}\right)$ & 0.08 & 0.15 \\
\hline \multirow{2}{*}{90} & Sound mean value $\left({ }^{\circ}\right)$ & 139.47 & 138.44 & 140.62 & Mean value $\left({ }^{\circ}\right)$ & -0.02 & -0.02 \\
\hline & Sound std value $\left(^{\circ}\right)$ & 1.21 & 1.16 & 1.11 & Std value $\left(^{\circ}\right)$ & 0.14 & 0.26 \\
\hline
\end{tabular}

\subsection{Influence of the number of analysed cycles and position with respect to the initial temperature value $T_{0}$.}

The number of analysed cycles has been considered as a process parameter. In particular, the number of cycles (Figure 10 and 11) and the effect of the position of 3 cycles (Figure 12) within the analysis of the thermal sequence were reported for the period of $45 \mathrm{~s}$ with the sine wave. No significant differences were observed in the results about the position of the cycles and the number of cycles up to 6 (Table 6). However, a slight decrease in terms of standard deviation (therefore a higher signal-to-noise ratio) has been observed for 30 analysed (period $9 \mathrm{~s}$, Figure 13) cycles even if, the steady-state value of the mean temperature has been reached anymore (Table 7). Moreover, the analysis of 3 cycles shifted to higher average temperature levels leads to an evident increase of the noise with respect to the first 3 cycles (13).
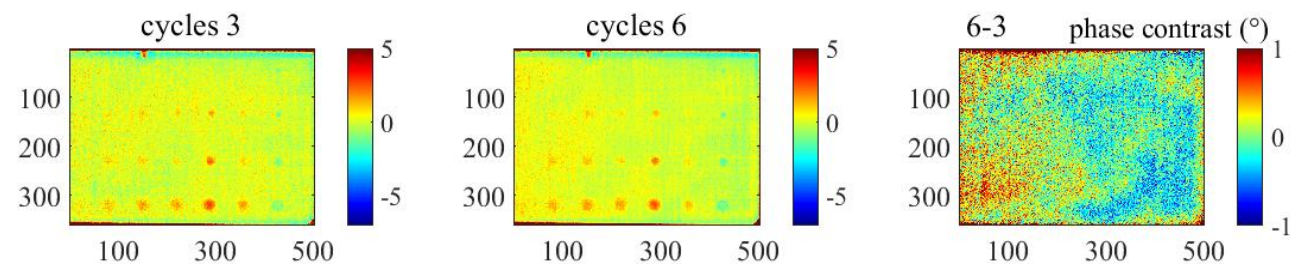

Fig. 10. Effect of the number of analysed cycles; sine $45 \mathrm{~s}$ ( $5 \mathrm{~Hz}$, approximation polynomial degree 1), phase contrast maps by analysing 3 cycles and 6 cycles and related "difference map" 6-3 cycles. 


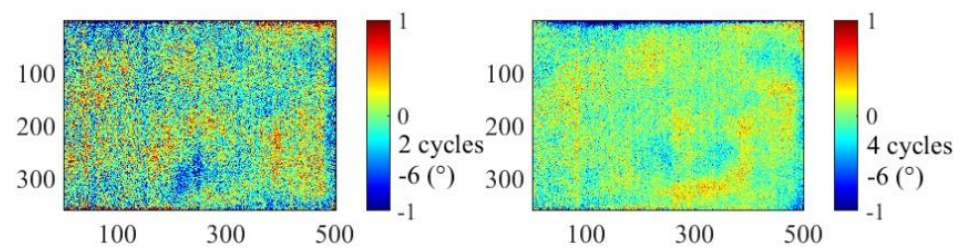

Fig. 11. Effect of the number of the analysed cycles; sine 45 s, "difference maps" 2-6 cycles, 4-6 cycles.
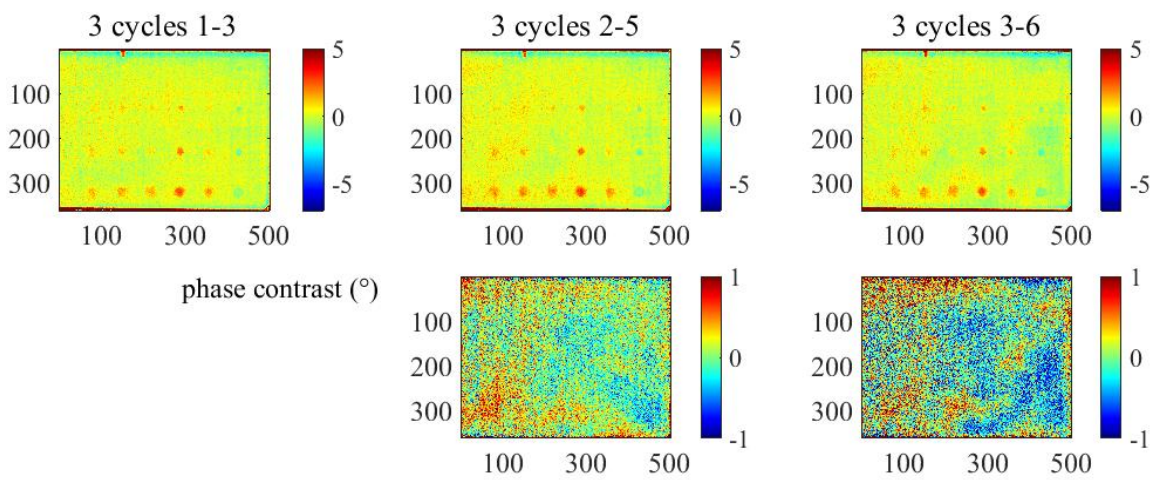

Fig. 12. Effect of the position of the analysed cycles sine $45 \mathrm{~s}$, phase contrast maps and related "difference maps" (2-5) - (1-3) cycles, (3-6) - (1-3) cycles.
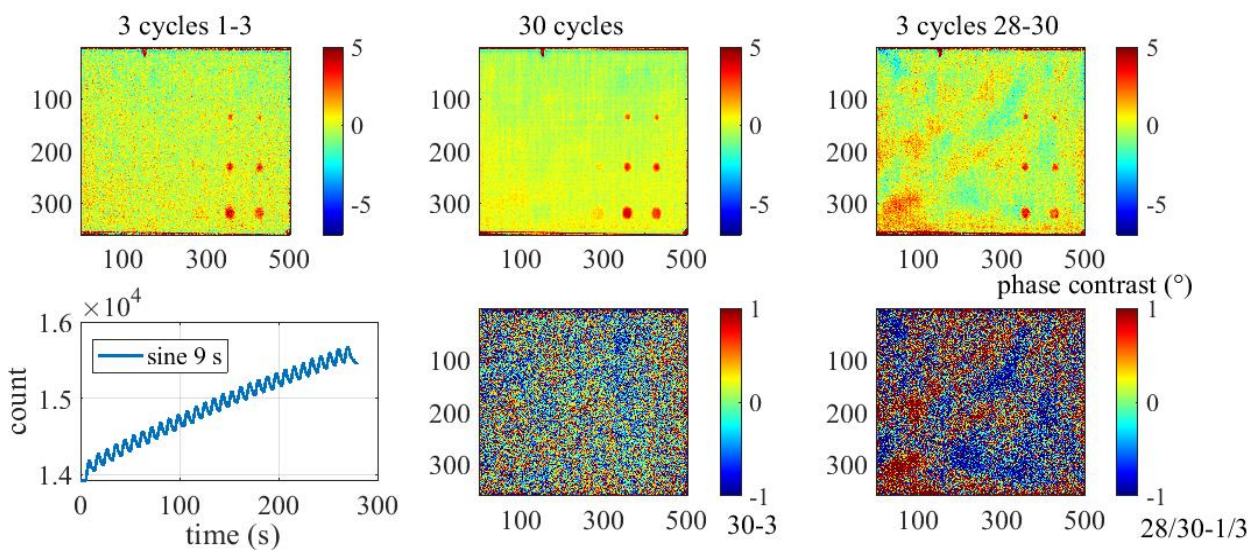

Fig. 13. Effect of the number and the position of the analysed cycles; sine $9 \mathrm{~s}(5 \mathrm{~Hz}$, approximation polynomial degree 1), phase contrast maps by analysing 3 cycles, 30 cycles and 3 cycles in position 28-30 and related "difference maps".

Table 6. Effect of the number and the position of the analysed cycles: Mean and standard deviation values of the sound area of the related phase maps, sine $45 \mathrm{~s}$.

\begin{tabular}{|c|c|c|c|c|c|c|c|c|}
\hline Number of cycles & $\begin{array}{c}2 \\
\text { cycles }\end{array}$ & $\begin{array}{c}3 \\
\text { cycles }\end{array}$ & $\begin{array}{c}4 \\
\text { cycles }\end{array}$ & $\begin{array}{c}6 \\
\text { cycles }\end{array}$ & Differences maps & $2-6$ & $6-3$ & $4-6$ \\
\hline Sound mean value $\left(^{\circ}\right)$ & -120.98 & -121.88 & -120.92 & -120.64 & Mean value $\left(^{\circ}\right)$ & -0.05 & 0.03 & 0.00 \\
\hline Sound std value $\left(^{\circ}\right)$ & 1.09 & 0.88 & 0.98 & 0.95 & Std value $\left(^{\circ}\right)$ & 0.47 & 0.42 & 0.24 \\
\hline
\end{tabular}

\begin{tabular}{|c|c|c|c|c|c|c|}
\hline $\begin{array}{c}\text { "Position" of cycles } \\
\text { respect to the } T_{0}\end{array}$ & $\begin{array}{c}1-3 \\
\text { cycles }\end{array}$ & $\begin{array}{c}2-5 \\
\text { cycles }\end{array}$ & $\begin{array}{c}3-6 \\
\text { cycles }\end{array}$ & $\begin{array}{c}\text { Differences } \\
\text { maps }\end{array}$ & $\begin{array}{c}2-5 \\
\text { Minus } \\
1-3\end{array}$ & $\begin{array}{c}3-6 \\
\text { Minus } \\
1-3\end{array}$ \\
\hline Sound mean value $\left(^{\circ}\right)$ & -121.88 & -120.79 & -120.49 & Mean value $\left(^{\circ}\right)$ & 0.04 & 0.04 \\
\hline Sound std value $\left(^{\circ}\right)$ & 0.88 & 0.93 & 0.97 & Std value $\left(^{\circ}\right)$ & 0.40 & 0.55 \\
\hline
\end{tabular}

Table 7. Effect of the number and the position of the analysed cycles: Mean and standard deviation values of the sound area of the related phase maps, sine $9 \mathrm{~s}$.

\begin{tabular}{|c|c|c|c|c|c|c|}
\hline Number of cycles & $\begin{array}{c}3 \\
\text { cycles }\end{array}$ & $\begin{array}{c}30 \\
\text { cycles }\end{array}$ & $\begin{array}{c}28-30 \\
\text { cycles }\end{array}$ & $\begin{array}{c}\text { Differences } \\
\text { maps }\end{array}$ & $30-3$ & $\begin{array}{c}28-30 \\
\text { Minus }\end{array}$ \\
\hline
\end{tabular}




\begin{tabular}{|c|c|c|c|c|c|c|}
\hline & & & & & & $1-3$ \\
\hline Sound mean value $\left(^{\circ}\right)$ & -70.75 & -67.64 & 151.31 & Mean value $\left(^{\circ}\right)$ & 0.01 & 0.05 \\
\hline Sound std value $\left(^{\circ}\right)$ & 0.93 & 0.58 & 1.19 & Std value $\left(^{\circ}\right)$ & 0.81 & 1.32 \\
\hline
\end{tabular}

\subsection{Influence of the frame rate (number of frames per cycle)}

As already demonstrated in Palumbo's work [4], the frame rate and therefore the number of frames per cycle influences the results. An example of analysis and relative results is reported in the case of the 45-90 seconds software multifrequency test in Figure 14. In this part, the period of 45 seconds has been considered, sub-sampling the original thermal sequence. The "differences maps", as well as the standard deviation values reported in Table 8, indicate as the level of noise of the sound areas increases as the frame rate decreases. The difference maps show also the variation of the defects contrast that decreases as the frame rate decreases (defects appear in difference phase maps).

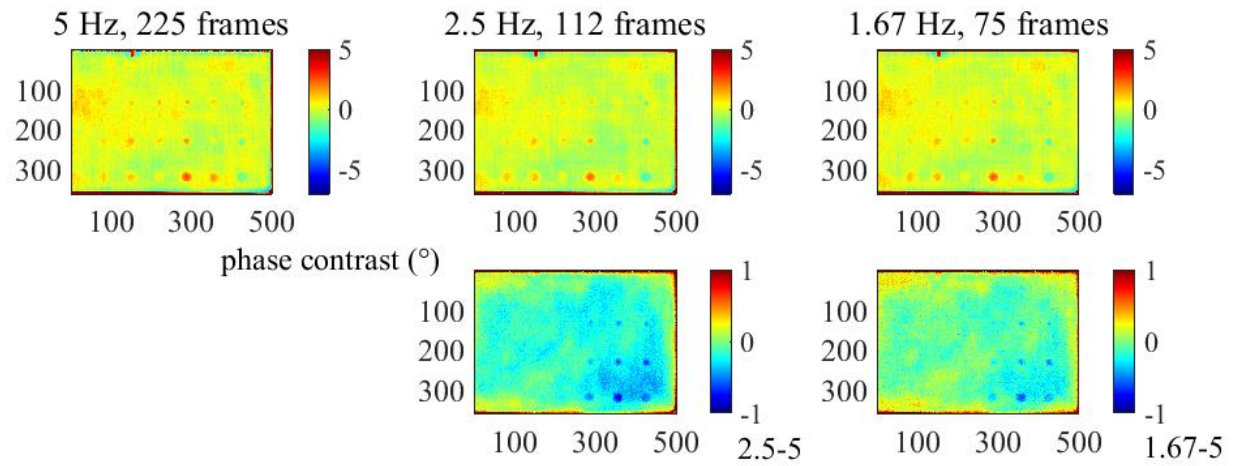

Fig. 14. MFS 45-90 s, phase contrast maps by analysing the original sequence, $5 \mathrm{~Hz}-225$ frames, the same sequence with $2.5 \mathrm{~Hz}-112$ frames and with 1.67 Hz-75 frames and related "difference maps".

Table 8. Effect of the frame rate: Mean and standard deviation values of the sound area of the related phase maps, MFS 45-90 s.

\begin{tabular}{|c|c|c|c|c|c|c|}
\hline $\begin{array}{l}\text { Frame rate }(\mathrm{Hz}) \\
\text { Frames per cycle }\end{array}$ & $\begin{array}{l}5 \mathrm{~Hz} \\
225 \\
\end{array}$ & $\begin{array}{c}2.5 \mathrm{~Hz} \\
112 \\
\end{array}$ & $\begin{array}{c}1.67 \mathrm{~Hz} \\
75\end{array}$ & $\begin{array}{c}\text { Differences } \\
\text { maps }\end{array}$ & $2.5-5$ & $1.67-5$ \\
\hline Sound mean value $\left(^{\circ}\right)$ & 140.22 & 151.88 & 146.79 & Mean value $\left(^{\circ}\right)$ & 0.06 & 0.06 \\
\hline Sound std value $\left(^{\circ}\right)$ & 0.96 & 1.08 & 1.07 & Std value $\left(^{\circ}\right)$ & 0.25 & 0.24 \\
\hline
\end{tabular}

\subsection{Influence of the waveform and therefore of the excitation period}

The final comparison regards the various waveforms and in particular the results obtained from MFS and MFH tests. Only the results obtained with 45 seconds and with the related higher harmonics are reported, but similar results and considerations can be done for the other periods. All the analyses were carried out with the same parameters, i.e. in this case, $45 \mathrm{~s}$, degree of polynomial approximation 1, 6 cycles, $5 \mathrm{~Hz}$, frame number 1350; in particular the principal harmonic of all the tests appears absolutely comparable (Figures 15 and 16). The subsequent harmonics are noisier, especially those coming from the MFS test; the MFH test instead provides results very similar to those of a 45 second square wave test, in fact very similar are the obtained standard deviation values (Table 9). However, the MFH approach needs a suitable set-up that depends on the component geometry. Indeed, in case of complex geometries of the component, could be very hard to set the source position to guarantee the uniform heating of the component. In this regard, the MFS test seems more robust since it requires only a signal input to control simultaneously the heat sources.

Table 9. Mean and standard deviation values of the sound area of the related phase maps, final comparison with different waveforms (MFH-MFS-sine-square).

\begin{tabular}{|c|c|c|c|c|c|c|c|c|c|}
\hline $\begin{array}{c}\text { Period } \\
\left(\mathrm{s}^{-}\right. \\
\text {MFS })\end{array}$ & Waveform & MFH & MFS & sine & square & $\begin{array}{c}\text { Differences } \\
\text { maps }\end{array}$ & $\begin{array}{c}\text { MFH- } \\
\text { sine }\end{array}$ & $\begin{array}{c}\text { MFS- } \\
\text { sine }\end{array}$ & $\begin{array}{c}\text { square- } \\
\text { sine }\end{array}$ \\
\hline \multirow{2}{*}{$9\left(5^{\text {th }}\right)$} & Sound mean value $\left(^{\circ}\right)$ & -23.50 & -26.11 & -69.28 & 150.31 & Mean value $\left(^{\circ}\right)$ & 0.24 & 0.07 & 0.13 \\
\cline { 2 - 12 } & Sound std value $\left(^{\circ}\right)$ & 1.48 & 1.92 & 0.75 & 1.29 & Std value $\left(^{\circ}\right)$ & 1.59 & 2.00 & 1.39 \\
\hline \multirow{2}{*}{$15\left(3^{\text {rd }}\right)$} & Sound mean value $\left(^{\circ}\right)$ & 148.61 & 146.90 & -152.88 & 144.48 & Mean value $\left(^{\circ}\right)$ & 0.06 & 0.03 & 0.10 \\
\cline { 2 - 11 } & Sound std value $\left(^{\circ}\right)$ & 1.12 & 1.05 & 0.66 & 0.94 & Std value $\left(^{\circ}\right)$ & 1.08 & 1.07 & 0.97 \\
\hline \multirow{2}{*}{$45\left(1^{\text {st }}\right)$} & Sound mean value $\left(^{\circ}\right)$ & 140.48 & 140.22 & -120.64 & 139.10 & Mean value $\left(^{\circ}\right)$ & 0.04 & 0.06 & 0.09 \\
\cline { 2 - 11 } & Sound std value $\left(^{\circ}\right)$ & 0.81 & 0.96 & 0.95 & 0.93 & Std value $\left(^{\circ}\right)$ & 0.63 & 0.59 & 0.62 \\
\hline
\end{tabular}




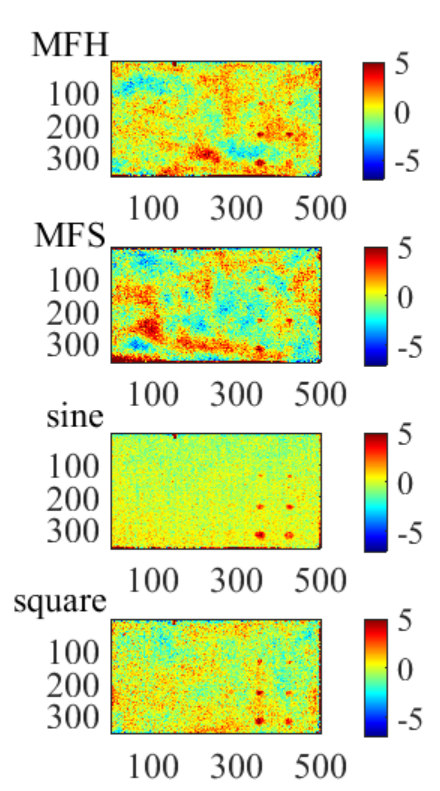

(a)
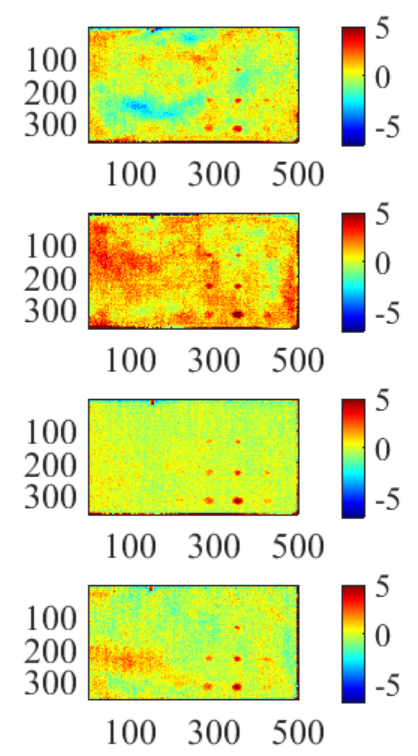

(b)
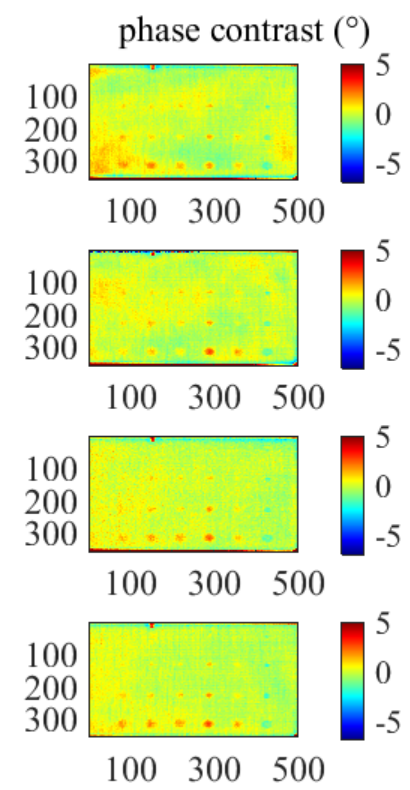

(c)

Fig. 15. Final comparison among the different waveforms (MFS-MFH-sine-square) for different excitation periods; phase contrast maps $9 s$ (a), $15 s$ (b), $45 s$ (c).

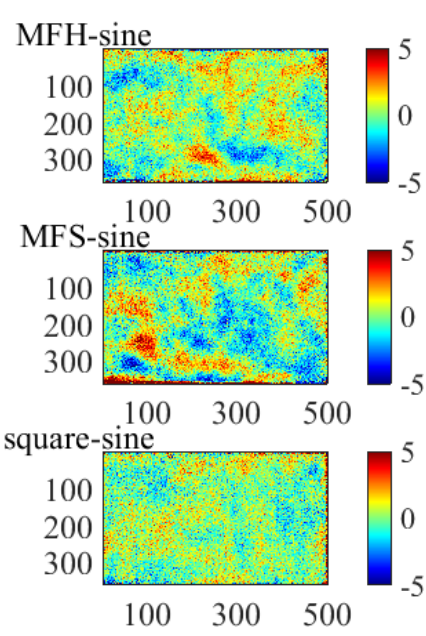

(a)
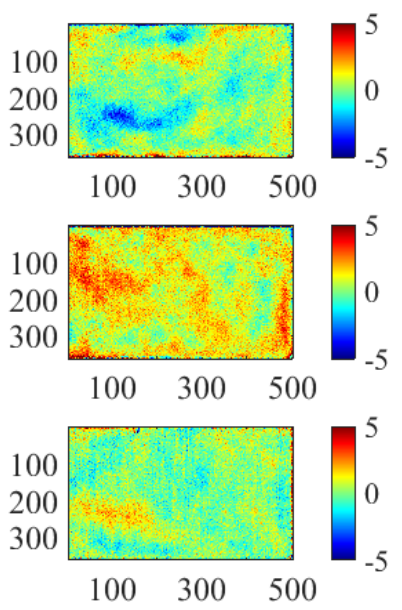

(b)
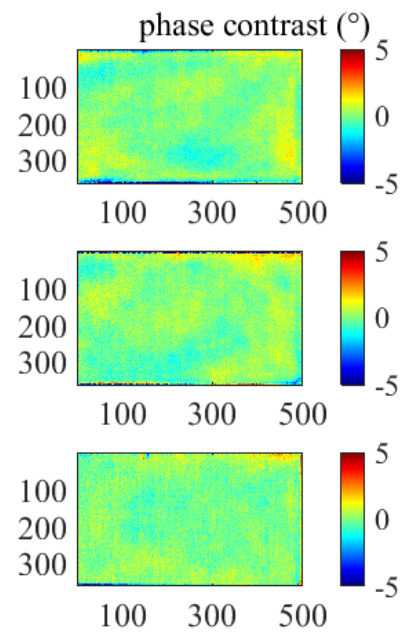

(c)

Fig. 5. Final comparison among the different waveforms (MFH-MFS-sine-square) for different excitation periods; "difference maps" MFH-sine MFS-sine square-sine $9 s$ (a), $15 s$ (b), $45 s$ (c).

\section{Discussion of the results}

In this section we focused on the phase contrast achieved for each defect when the excitation mode changes, leaving the other parameters fixed. As an example of results, the comparison obtained by analysing the main harmonic at 45 seconds and the subsequent higher harmonics, for the defects of the second row, is reported in Figure 17 (diameter 10 $\mathrm{mm}$, different depths and different materials). For each defect, the signal to noise ratio is reported in the different bar plots, dividing the phase contrast by the standard deviation of the sound area around the defect (about 1000 pixels), reported also as an error bar in the various graphs.

Similar considerations to the previous ones (section 5.14) emerge from the analysis of the first harmonic when the single defect is examined (Figure 17). In particular, the contrasts achieved with the MFH test are always comparable with the similar test with the sine wave. The good signal noise ratio, as already specified, is due to the simultaneous use of a longer excitation period (MFH 45-90 s). For subsequent harmonics (Figures 18 and 19) the signal-to-noise ratio is instead higher in the case of a sine wave, but the number of detectable defects remains the same. The presence of phase 
contrasts with a different sign is due to the excitation period with respect to the material and the depth of the defect. Similar considerations can be done for defects of different diameter (Figures 18 and 19).
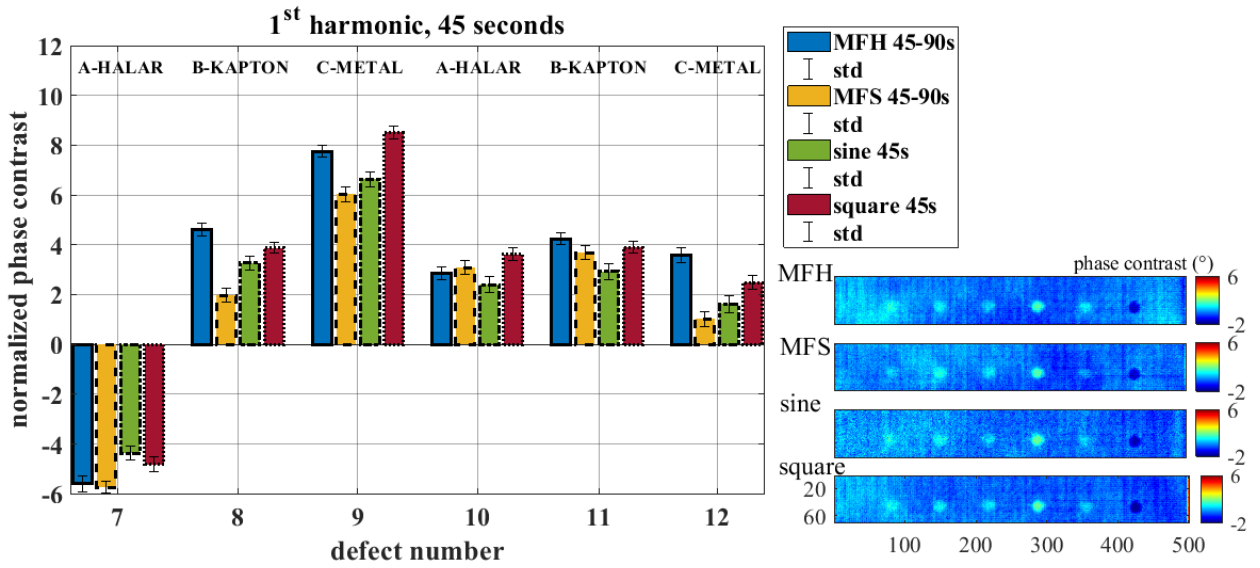

Fig. 17. Final comparison among the different waveforms (MFS-MFH-sine-square), excitation period 45 seconds, $1^{\text {st }}$ harmonic, $5 \mathrm{~Hz}, 6$ cycles, 1350 frames, polynomial degree 1, defects 7-12, diameter $10 \mathrm{~mm}$ different depths and materials.
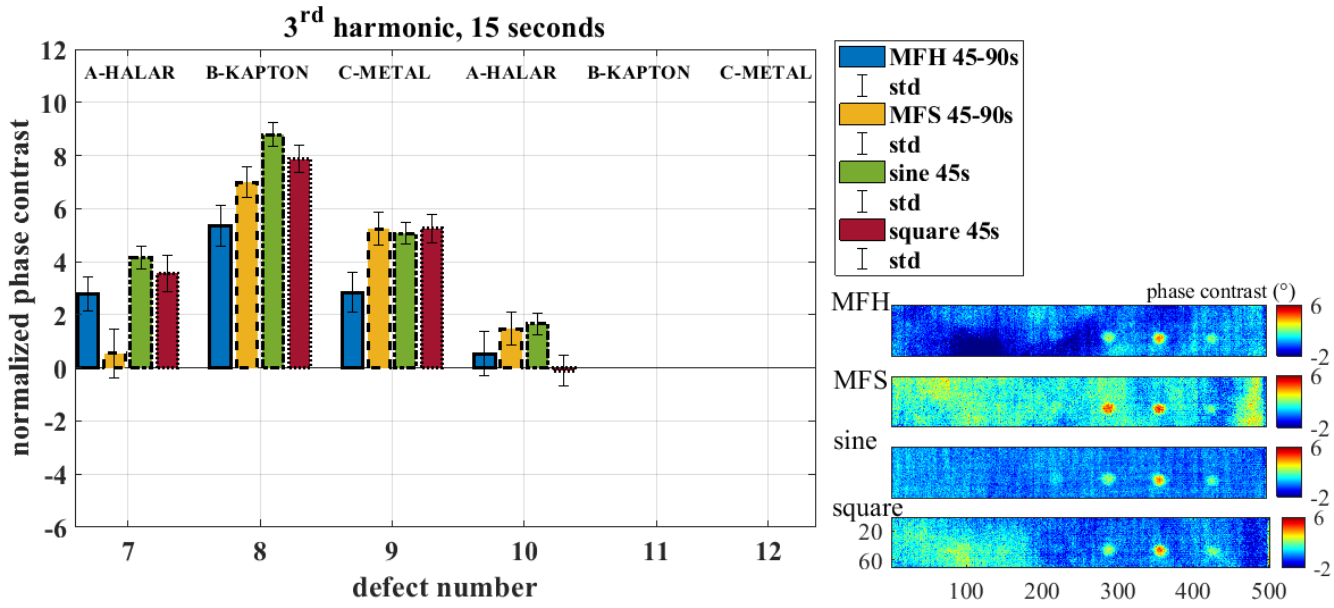

Fig. 6. Final comparison among the different waveforms (MFS-MFH-sine-square), excitation period 15 seconds, $3^{\text {rd }}$ harmonic, $5 \mathrm{~Hz}, 6$ cycles, 1350 frames, polynomial degree 1, defects 7-12, diameter $10 \mathrm{~mm}$ different depths and materials.
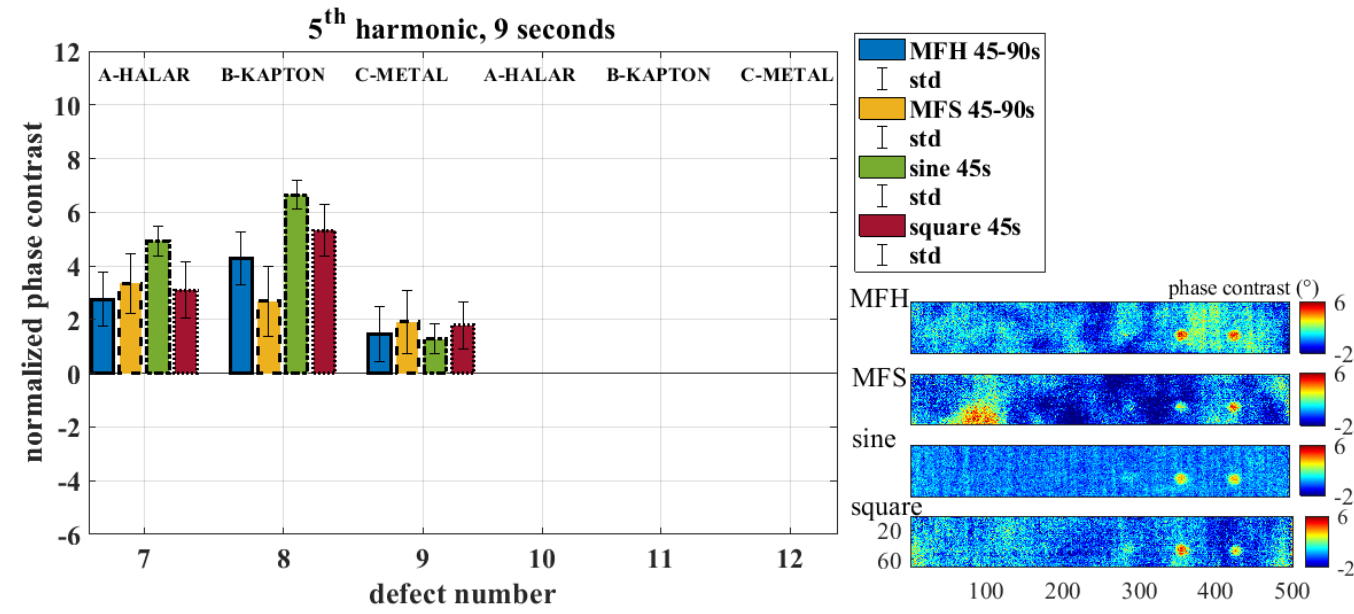

Fig. 7. Final comparison among the different waveforms (MFS-MFH-sine-square), excitation period 9 seconds, $5^{\text {th }}$ harmonic, $5 \mathrm{~Hz}, 6$ cycles, 1350 frames, polynomial degree 1, defects 7-12, diameter $10 \mathrm{~mm}$ different depths and materials. 


\section{Conclusions and outlooks}

In this work, different ways/modes to perform a lock-in thermographic test have been examined, proposing two new approaches in order to limit the time of trial and data analysis, a hardware multifrequency approach, and a software multifrequency one. With very short test and analysis times, it is possible to obtain from a single test, information relating to 6 different periods of excitation and therefore to 6 depths of the inspected material. Both proposed approaches require hardware and software instrumentation capable of exciting the component under examination with different levels of input energy in different instants of time, in order to compose the waves of the individual periods. A detailed test and analysis plan have been structured in order to investigate the influence of some fundamental parameters such as the number of cycles and their position with respect to the initial temperature value $T_{0}$, the analysis frame rate and the polynomial degree approximation of the mean temperature, as well as the excitation period and the thermal waves (MFH, MFS, sine and square). Tests and analyses were carried out on a CFRP specimen with different imposed defects, in terms of material, size and depth. The main results can be summarized as follows:

$>$ There is a fair influence of the polynomial degree of approximation used to model the average temperature growth of the material, on the quality of results in terms of the signal noise. The standard deviation values decrease as the degree of approximation of the average increases (although the processing times increase), especially for long periods of thermal excitation (i.e. 90 seconds).

$>$ The analysis of the number of cycles shows that the lower level of noise is obtained starting the analysis from $\mathrm{T}_{0}$ (classical analysis) while increasing the number of analysis cycles does not lead to significant improvements of phase data (the signal-to-noise ratio increases but the number of indications detectable it does not change).

$>$ The frame rate influences the quality of results, but other analyses with different periods are necessary to have a quantitative evaluation of this effect.

$>$ The hardware multifrequency approach leads to better results in terms of signal to noise ratio than the software multifrequency ones but the first one requires a less flexible set up depending on the component geometry.

$>$ The results obtained are comparable with those obtained adopting classical approaches such as sine or square wave. The higher harmonics coming from the multifrequency approaches present higher noise, but they can be very useful for an initial screening to detect defects and to obtain information about the suitable periods for performing the quantitative defects characterization.

Future works will concern the systematic study of the influences studied and shown in this work through a Design of Experiments (DOE) analysis, replicating tests, and considering the significant factors.

\section{REFERENCES}

[1] Maldague, X. P. (2012). Nondestructive evaluation of materials by infrared thermography. Springer Science \& Business Media.

[2] D’Accardi, E., Palano, F., Tamborrino, R., Palumbo, D., Tatì, A., Terzi, R., \& Galietti, U. (2019). Pulsed phase thermography approach for the characterization of delaminations in cfrp and comparison to phased array ultrasonic testing. Journal of Nondestructive Evaluation, 38(1), 20.

[3] Maierhofer, C., Röllig, M., Krankenhagen, R., \& Myrach, P. (2016). Comparison of quantitative defect characterization using pulse-phase and lock-in thermography. Applied optics, 55(34), D76-D86.

[4] Palumbo, D., \& Galietti, U. (2016). Damage investigation in composite materials by means of new thermal data processing procedures. Strain, 52(4), 276-285.

[5] Pitarresi, G. (2015). Lock-in signal post-processing techniques in infra-red thermography for materials structural evaluation. Experimental Mechanics, 55(4), 667-680.

[6] Montanini, R. (2010). Quantitative determination of subsurface defects in a reference specimen made of Plexiglas by means of lock-in and pulse phase infrared thermography. Infrared Physics \& Technology, 53(5).

[7] Mulaveesala, R., \& Tuli, S. (2006). Theory of frequency modulated thermal wave imaging for nondestructive subsurface defect detection. Applied Physics Letters, 89(19), 191913.

[8] Meola, C., Carlomagno, G. M., Squillace, A., and Giorleo, G. (2002). Non-destructive control of industrial materials by means of lock-in thermography. Meas. Sci. Technol. 10, 1583-1590. 9. Usamentiaga, R.,

[9] Venegas, P., Guerediaga, J., Vega, L., and Lòpez, I. (2013). Feature extraction and analysis for automatic characterization of impact damage in carbon fiber composites using active thermography. NDT\&E Int. 54, 123132.

[10] Ibarra-Castanedo, C. (2005). Quantitative subsurface defect evaluation by pulsed phase thermography: depth retrieval with the phase, Ph.D. thesis, Université Laval.

[11] Palumbo, D., Tamborrino, R., Galietti, U., Aversa, P., Tati, A., and Luprano, V. A. M. (2015). Ultrasonic analysis and lock-in thermography for debonding evaluation of composite adhesive joints. NDT\&E Int. 78, 1-9.

[12] Pitarresi, G. (2010) Thermal NDE of thick GRP panels by means of a pulse modulated lock-in thermography technique. 14th International Conference on Experimental Mechanics, ICEM 2014, Poitiers, France, 4-9 July 2010. EPJ Web of Conferences, Volume 6, 9 June 2010, Article number 38014.

[13] IRTA Manual (2015). Diagnostic Engineering Solutions (DES srl). 